\title{
(2) \\ Ancestral Genetic Resources Provide an Alternative to GMO Crops.
}

\author{
Mary W. Eubanks
}

\begin{abstract}
Concern about the effects of pesticides on human health and the environment, has been a major rationale for promoting transgenic crops, often referred to as genetically modified organisms (GMOs), or as genetically enhanced (GE) crops. Companies that sell genetically engineered crop plants claim that biotechnology offers a safe alternative to agricultural chemicals and is necessary to feed the world's expanding human population. However, there are still many unknowns about the safety of GMOs for human health and the environment, and virtually nothing is known about how the genomes of organisms may be affected by horizontal transfer of alien genes into plants, animals, and even humans. An alternative approach to transgenic technology is the exploitation of beneficial genes from wild relatives of crop plants using conventional breeding methods. This paper describes how genetic engineering differs from conventional plant breeding, then compares and contrasts benefits from transgenic engineering with traditional methods of crop improvement. An example of how the ancestral genes model has been employed to impart an insect resistance trait to corn based on native resistance from a wild relative is compared to transgenic corn with resistance to the same insect engineered with a transgene from a bacterium. Using the ancestral genes approach, harmful chemicals used to control the worst insect pest of corn can be eliminated with no consequences to human health or the environment; whereas with the transgenic approach, there are many safety concerns in both arenas.
\end{abstract}

\section{Ancestral Genes Model}

\section{Basic Concept}

Three basic steps are involved in the ancestral genes model for crop improvement: (1) identify the wild progenitors of the crop plant; (2) make experimental crosses between the progenitor taxa and recover fertile hybrids;
(3) employ selected recombinant progeny as a genetic bridge to transfer the recovered ancestral genes into the crop. Although crossing different crop varieties and selecting novel recombinant progeny with useful traits has been the standard method of plant breeders since agriculture began (Duvick 2001), a better understanding of chromosome recombination, combined with the tools of molecular genetics, makes the ancestral genes approach more precise and efficient than previously possible. Cytogenetic study combined with comparative genomics is the key to correctly identifying the progenitor taxa for reconstructing prototypes of the domesticated crop.

\section{Chromosome Architecture}

Cytogenetic study is necessary to correctly identify likely candidates for wide cross compatibility. Similarities in chromosome architecture, rather than same chromosome number, signal feasibility of producing viable progeny from recombination between differing genomes. This is an important distinction because the conventional wisdom of genetics and biotechnology is that hybrids are produced by crossing related species with the same

\section{Correspondence}

Mary W. Eubanks, Department of Biology, Duke University, Durham, NC 27708-0338, U.S.A., e-mail: eubanks@duke.edu

Ethnobotany Research \& Applications 1: 21-29 (2003) 
chromosome number (Bennetzen et al. 2001). A majority of crop plants, including wheat, cotton, tobacco, tomatoes, and sugarcane to mention a few well characterized examples, originated from human selection of natural hybrids between wild relatives of the crop. In wide cross hybridization, the chromosome number of the progeny does not necessarily equal the sum of the haploid number of each parent (Jensen 1989; John \& Freeman 1975; McClintock 1984; Singh 1993; Wagner et al. 1993). When species with different chromosome numbers recombine, the chromosome number of the progeny often stabilizes at the same number of the parent with the lowest number. The chromosome number test will fail to detect recombinant progeny resulting from such cryptic interspecific or intergeneric hybridization combining the genomes of two taxa with different chromosome numbers. The phenomenon of genomic reorganization via chromosome rearrangements, elimination of targeted chromosomes in interspecific hybrids, and formation of diploid hybrids instead of expected polyploids has been characterized in a number of crops (Chetelet et al. 1989; Davies et al. 1990; Jenkins et al.1988; Jenkins \& White 1990; Linde-Laursen \& von Bothmer 1988; Mikklesen et al. 1996; White et al. 1988). These phenomena have also been shown to occur in wide cross hybrids found in nature (Arnold 1997; Lord \& Richards 1977; Stebbins 1950). Therefore, it is critical that the search for ancient crop progenitors not be restricted to the false assumption that only species with the same chromosome number are able to recombine to produce viable hybrids, and the equally misleading assumption that the chromosome number of ancestral taxa must be the same as the domesticated crop.

\section{Comparative Genomics}

A better understanding of the genetic affinities between wild relatives of crop plants may enhance plants breeders' ability to identify new sources of genetic variation that could be valuable for crop improvement. Accurate knowledge of the phylogenetic history through comparative genomics may aid characterization of the genetic mechanisms governing crossability of germplasm in breeding programs and crop plant evolution. With the advent of molecular mapping, comparative genomics can be employed to identify closely related taxa that have previously been overlooked because of cryptic rearrangements (Rieseberg \& Wendell 1993). Genes that are the same but occupy different chromosome positions and orientations in different taxa can be identified by DNA fingerprinting. For example, we now know grass genomes are essentially differentiated by the amount of repetitive DNA and large-scale chromosomal rearrangements (Moore et al. 1995), and approximately $20-40 \%$ of markers on recombinational maps do not exhibit collinearity or synteny (Bennetzen \& Freeling 1997; Gale \& Devos 1998). Subtle speciation mechanisms such as small-scale rearrangements that perturb local gene composition and order (i.e. microcolinearity) and other exceptions to collinearity and synteny, that have previously gone undetected in phylogenetic studies can be revealed by comparative examination of the genomic profiles of wild plants related to crops. Therefore, when DNA fingerprinting is combined with cytological study it is possible to make more precise predictions about likely wild relative progenitors of the crop that were previously undetected.

\section{Recurrent Selection}

Once the likely wild relatives have been identified, controlled cross-pollinations between potential progenitors are made to determine which crosses yield fertile hybrids. DNA fingerprinting is then employed to genotype hybrids and parents to characterize ancestral prototypes of ancient gene pools. Ancestral prototype hybrids can then be used as a genetic bridge to transfer desirable resurrected genes into the modern crop plant (Hadley \& Openshaw 1980). Finally, recombinant hybrids with traits of interest are selected, and improved hybrid lines developed through a recurrent selection molecular marker-assisted breeding program. This model for recapturing ancestral genes for crop improvement offers an alternative to transgenic crops, commonly referred to as GMOs (genetically modified organisms).

\section{Genetically Modified Organisms}

\section{Technology Fundamentals}

In agriculture, the term GMO (genetically modified organism) refers to a plant that has been modified by the introduction of foreign DNA, i.e. genetic material that is not native to the target species itself (Griffiths et al. 1993). In GMO crop plants, a gene from a bacterium, animal, other plant, or a synthesized gene constructed in the laboratory that does not occur in nature, such as a gene for herbicide tolerance, is linked to a reporter gene (often an antibiotic resistance gene), and other DNA sequences required for proper insertion and expression in the host plant genome. This chimeric DNA is spliced into a bacterial plasmid, inserted into a viral or bacterial vector by conjugation, and introduced into the crop by infecting the plant with the genetically engineered pathogen, or by mechanical means such as a gene gun or electric shock treatment. Biotechnologists argue that genetic engineering is no different from conventional plant breeding methods in which beneficial traits are artificially selected from natural biodiversity within recombinant crosses, land races, and wild relatives. This simplistic rationale is misleading because it ignores possible consequences of biotechnology's revolutionary capability of crossing genetic boundaries not possible in nature (Meyer 1998; Palumbi 2001a, 2001b). Even so, government regulation of the biotechnology industry is based on this misguided assumption. Transgenic crop plants have been deployed into open environment systems around the world, and GM products have been widely distributed in the global food supply. 


\section{Benefits}

Companies selling genetically engineered seed promote biotechnology as necessary to feed the world and reduce the use of agricultural chemicals (Charman 2001; Nash 2000; The Economist 1999; Wolfenbarger \& Phifer 2000). Beneficial traits derived from GMO technology include insect resistance, pathogen resistance, herbicide tolerance, longer shelf life in the supermarket, drought resistance, ability to fix nitrogen, ability to manufacture nutraceuticals, etc. Another putative benefit of genetic engineering that industry advocates in its favor is that it allows new traits for crop improvement to be developed more rapidly and efficiently than can be done using conventional plant breeding methods.

\section{Risks}

Because GMO technology employs DNA from widely disparate organisms and/or genes created in the laboratory, by design, it must overcome the boundaries of evolutionary genetics that have evolved to protect and insure organismal genomic integrity and stability. Thus, GMOs may pose a number of potential risks to humans and the environment (WHO 2000). For instance, in GM crops engineered for insect resistance, the pesticidal toxin is produced throughout the plant, including the part eaten for food. Individuals may have allergic reactions to the transgenic protein (Keeler 2001; Nordlee et al. 1996; Wheelwright \& Delin 2001). Insecticidal proteins that kill target insects are also lethal to beneficial insects in the environment, as demonstrated by lethality to Monarch butterfly larvae that consume Bt corn pollen (Losey et al. 1999; Obrycki et al. 2001). Target insects develop resistance to transgenic toxins (Huang et al. 1999; Obrycki et al. 2001) just as they do to agricultural pesticides, and this leads to even more serious insect problems for agriculture. Transgenes can be transferred by wind, insect, or animal pollinators into non-GMO and organic crops, as well as wild plants in the natural environment (Goldburg 1992; Mikkelsen et al. 1996; Obrycki et al. 2001; Raybould and Gray 1994). This has potential for swamping out natural biodiversity, and could possibly lead to development of weeds resistant to the herbicides used to eliminate them.

Because of our limited knowledge of DNA expression, regulation, and function, as well as how different organisms respond to threats to genomic integrity (McClintock 1984), there will probably be consequences of GMO technology that cannot be anticipated or imagined. Another risk about which virtually nothing is known is possible horizontal transfer of transgenes from plants to environmental bacteria, and from plant products consumed as food to gut microorganisms or even human cells (American Medical Association 2001). Although such transfer of DNA was generally not thought possible beyond outcrossing to wild relatives in nature, it has now been scientifically documented that a synthetic transgene for herbicide resistance in oilseed rape has moved into bacteria living in the gut of honey bees (Ag Biotech Reporter 2000a). More recently, a team of scientists at the University of Illinois demonstrated transfer of antibiotic resistance genes from intestinal bacteria to human cells (Ag Biotech Reporter 2001).

\section{Regulatory Agencies}

Three United States agencies are responsible for insuring the safety of genetically engineered plants and animals (National Research Council 2000). The U. S. Department of Agriculture (USDA) oversees field trials involving plants modified through biotechnology. The Food and Drug Administration (FDA) regulates food and feed safety, and reviews the applicant's data package confirming that food or feed products are safe for consumption. The Environmental Protection Agency (EPA) regulates plant protection trials, such as insect resistance. The EPA also regulated labels for herbicide usage on herbicide-tolerant plants.

\section{Safety Standards}

Regulatory protocols to determine safety of GMOs are based on standards set for regulating agricultural chemicals (National Research Council 2000). The objectives of pesticide regulations are to prevent humans from consuming excessive amounts of a harmful toxin in food, and to restrict release of excessive amounts of a harmful chemical into the environment. The uptake of the active ingredient of the pesticide into all parts of the plant is monitored. If levels exceed established safety parameters in the part consumed for food, use of the pesticide is restricted. Chemicals that meet environmental standards and are not absorbed by the parts of the plant used for human consumption are approved because they can be washed off before being used for food. A crucial distinction of GMOs, however, is that human consumption of the transgenic DNA and its pesticidal product is unavoidable because the pesticide is continuously produced inside the plant, including the part eaten for food. Furthermore, once a GM plant is released into an open environment system, dispersal of transgenes that can recombine with the DNA of other organisms in nature cannot be controlled. Consequently, human health and environmental effects are not adequately addressed when applying regulatory protocols for chemical pesticides to GMOs.

\section{Bt Example}

This weakness in the regulations is illustrated by the example of Bacillus thuriengensis (Bt), a bacterium that produces a natural protein toxic to insects. Bt is used as a natural insecticidal spray that is approved by EPA because it breaks down rapidly, is ecologically benign in the environment, is not absorbed by the plant, and is not present in food. The biotechnology industry has harnessed the insecticidal proteins derived from Bt to impart resistance into plants genetically engineered to carry these transgenes from Bt. Since Bt is approved for use as an insecticidal spray, it has been assumed that GM crops engineered with Bt genes are also safe. The fact that in GM crops the Bt toxin is continually produced inside the plant and the consumer (insect, human or other animal) ingests 
it whenever they eat any part of that plant has thus not been carefully addressed in tests to insure safety of those products even though the Cry series proteins from Bt are potent gastric proteolytic enzymes. This begs the question: is it scientifically sound to apply the same rules for externally applied chemicals to toxins generated internally within the crop?

\section{Substantial Equivalence}

Related to this weakness in the regulatory rationale described above is the basic principle that governs regulation of food products and feed produced by biotechnology that is referred to as "substantial equivalence." Under the rule of substantial equivalence, if a protein or other compound produced by genetic modification is closely related in structure and function to other proteins or compounds found in plants, it will not be harmful to humans or animals. For example, Bt proteins have a close identity and are functionally similar to EPSPS proteins present in vegetables and baker's yeast. Therefore, Bt toxins incorporated into transgenic crop plants are "substantially equivalent" to natural compounds in food and are safe for human and animal consumption. However, this concept of "substantial equivalence" is a non sequitur that has potential to cause great harm because a single amino acid difference in a protein can completely alter its effect biochemically (Ewan \& Pusztai 1999; Kuiper 1999).

\section{StarLink Corn}

A complex example of the substantial equivalence rule is the StarLink corn fiasco (Devine 2000; Kaiser 2000; Wheelwright \& Dellin 2001). StarLink is Bt corn engineered with the Bt Cry9C protein that was produced and sold by Aventis, formerly Rh"ne Poulenc Ag. Although the regulatory agencies recognized that Cry9C was a potential human allergen, based on the substantial equivalence rule Aventis argued that Cry9C was safe. Though not yet for human consumption until more testing could be done, it was approved and marketed for animal feed in 2000. In spite of the regulatory restriction, taco shells sold at the fast food chain Taco Bell, whose parent company is Tricon Global Restaurants, Inc., tested positively for unapproved GMO corn in October, 2000 (New York Times, Oct. 3, 2000). After the discovery of the adventitious presence of StarLink corn in taco shells, it was eventually revealed that millions of bushels of StarLink corn had gone to food processors and widely contaminated foods from corn chips and corn flakes to all kinds of corn products (Washington Post, Oct. 19, 2000). In spite of massive recalls and EPA's withdrawal of Aventis' permit to sell StarLink corn, nine months later ten percent of the entire supply of cornseed worldwide is still contaminated with StarLink. A number of allergic reactions in people exposed to the Cry9C protein in StarLink corn have been reported, some life-threatening (www.cbsnews.com/now/story/0,1597,291992-412,00.shtml). Although, like other Bt toxins in GMOs, Cry9C is substantially equivalent to EPSPS proteins in plants, we can never really know how many people were affected by eating it, because most people would never associate milder allergic reactions such as skin irritation, stomach cramps, nausea, or diarrhea caused by eating corn chips, drinking a soft drink sweetend with corn syrup, or consuming some other product containing the allergen. This incident illustrates how widespread contamination of our food supply by GM seed is unavoidable due to gene flow in nature and simple human error.

Another scientific issue in regard to transgenic crop plants is movement of transgenes to non-GMO crops, weeds, and wild plants via cross-pollination by wind and insect pollinators (ChŠvre et al. 1997; Goldburg 1992; Lewis \& Palevitz 1999; Mikkelsen et al. 1996; NABC 1988, 1991; Raybould \& Gray 1994). For example, cross-pollination of a gene for herbicide tolerance could produce novel recombinant genotypes among wild plants in nature that are also resistant to the herbicide. This could lead to formation of super weeds that could create greater problems for agriculture than transgenic technology is intended to solve. It could also cause genetic swamping of native biodiversity and dramatically alter the balance of nature in ecosystems where this might occur. These are pragmatic scientific issues based on the principles of genetic recombination, evolutionary biology, and ecology.

Although the argument is often made that biotechnology is no different from artificial hybridization employed since the beginning of agriculture to develop new varieties of crops and breeds of animals, this is simply not true (Palumbi 2000a, 2000b). Biotechnology is revolutionary and different from anything that has gone before it. It provides unprecedented power to alter and accelerate evolution, and it is impossible to predict what kinds of changes widespread application of transgenic technologies will have over time. An unanticipated event signals how unprepared science is for the transformations that will occur. Molecular screening for the presence of the transgene for resistance to glyphosate in Monsanto's Roundup Ready soybeans revealed that the transgene has mutated and some seed now on the market does not have the same allele as the original transgenic seed that was approved. Transgenic events are not genetically stable, transgenes mutate easily, and they can induce mutations in the genomic DNA of their host organism. It is impossible to know when and where such mutations will occur, what effect they will have on genomic expression in the crop plants, and what the environmental and health effects of such de novo molecular products from mutated transgenes will be.

Consumers get mixed messages about GMO foods, and nations are polarized in their acceptance or rejection of GMOs (Snell 2001; Williams 1998). Most people do not have the sophisticated scientific knowledge and experience in industry and government regulatory affairs to understand that the "science-based" regulatory protocols fail to adequately address human health effects. Current safety tests have not been designed to encompass the 
broad spectrum of toxicological, ecological, and evolutionary genetic principles required for accurate assessment of the full impact releasing transgenes into an open-environment system may have. In light of such unknowns and potential risks, are there safe alternatives to genetically engineered crops? The answer is a resounding YES. One alternative is to tap the genetic diversity of the wild relatives of crop plants. This tried and true method of conventional plant breeding can be employed more effectively and efficiently using the new tools of molecular biology. An example that illustrates proof of concept for tapping ancestral genes for crop improvement follows.

\section{Ancestral Gene Model Proof of Concept}

Recent experimental evidence (Eubanks 1995, 1997, 2001a, 2001b; MacNeish \& Eubanks 2000) indicates the novel phenotypes that gave rise to domesticated maize were generated by intergeneric hybridization between two wild grasses, teosinte and Tripsacum. These recombinant mutants, which could not survive on their own in nature, were selected and preserved by humans for food. Corn was domesticated in the highlands of Mexico over 5,000 years ago at the end of the last Ice Age when the planet was warming and the food resources of prehistoric hunters and gatherers were changing in response to climate change.

\section{Gamagrass}

Eastern gamagrass, Tripsacum dactyloides L., is a wild relative of maize. It is a perennial that is endemic to eastern North America, and its range extends to northern South America. Tripsacum is a potentially rich source of beneficial traits for corn improvement (Berthaud et al. 1996, 1997; Burkhart et al. 1994; Eubanks 1989, 1992, 1994, 1995, 1996, 1997, 1998; Kindiger \& Beckett 1990; Kindiger \& Sokolov 1998; Leblanc et al. 1995; Savidan et al. 1996). In contrast to maize and teosinte, Tripsacum bears both staminate (male) and pistillate (female) flowers on the same spike, with the staminate flowers directly above the pistillate flowers. The gametic (n) chromosome number of Tripsacum is 18 (Berthaud et al. 1997). Although there have been literally thousands of attempts to cross annual teosinte, the closest relative of corn, with Tripsacum, they did not produce viable hybrids (Mangelsdorf 1974; Tantravahi 1968). Mangelsdorf \& Reeves (1931) were the first to successfully cross Tripsacum with corn, the basis of their hypothesis (1939) that hybridization between Tripsacum and an extinct wild corn gave rise to domesticated corn and annual teosintes. Production of (corn XTripsacum) hybrids, however, usually requires special pollinating techniques and embryo culture. (Corn XTripsacum) hybrids are sterile, but partial fertility can be restored in the pistillate florets by treatment with colchicine to induce chromosome doubling.

\section{Perennial Tesointe}

In the late 1970's, a perennial teosinte (Zea diploperennis Iltis, Doebley and Guzman) was discovered on the verge of extinction in the mountains of Jalisco, Mexico (Iltis et al. 1979). This diploid perennial teosinte is one of six species of teosinte endemic to Mexico and Guatemala, all of which are cross-fertile with corn. It is unique because it is a perennial with the same chromosome number as corn. However, its chromosome structure is more like Tripsacum than corn and other annual teosintes. Like Tripsacum, it has small knobs (dark-staining regions of repetitive DNA) at the ends of its chromosomes (Eubanks 2001a). Like Tripsacum, the sum of the length of its 10 chromosomes equals the sum of the length of the 18 Tripsacum chromosomes, a calculation that is $10 \%$ less than the sum of the length the 10 chromosomes of corn or other teosintes.

\section{Genetic Bridge Hybrid}

Because diploperennis is also a perennial with chromosome architecture similar to Tripsacum, Eubanks (1987) hypothesized the two genera could be successfully crossed, she obtained recombinant hybrids that are fully fertile by making controlled hand pollinations between perennial teosinte and Eastern gamagrass (Eubanks 1987, 1995, 1997, 2001a, 2001b). Because these hybrids are cross-fertile with corn, they overcome the problem of wide cross sterility between Tripsacum and corn, and serve as a genetic bridge for moving Tripsacum genes into corn. Beneficial traits that can be transferred to corn via this bridge using conventional plant breeding methods include insect resistance, disease resistance, drought resistance, cold tolerance, salt tolerance, ability to grow in acidic soils, ability to enhance nitrogen in soil around the plant's roots, improved grain quality with higher protein and other nutritional components. Proof of concept for this wide cross hybridization approach to crop improvement is demonstrated by successful transfer of resistance to corn rootworm from the Tripsacum-diploperennis hybrid into corn.

\section{Corn Rootworm}

Corn rootworm, Diabrotica sp., is a Coleopteran beetle that in the larval stage is one of the worst insect pests of corn in the United States Corn Belt. The economic costs, which include crop loss, costs of insecticides, and their application, can be as high as $\$ 1$ billion a year (Metcalf 1986). The eggs hatch during the summer and the larvae feed on corn roots. Because injury from this subterranean pest cannot be detected until damage has occurred and the potential loss is enormous, approximately 40 million acres, over half the acreage planted in corn in the United States, routinely receives at least one application of a soil insecticide annually (Eichers et al. 1978). Insecticides applied to prevent an outbreak of corn rootworm are harmful to humans and the environment. Tripsacum has natural resistance to corn rootworm (Branson 1971; Branson and Guss 1972; Moellenbeck, Barry and Darrah 1995). If this natural source of resistance can be effectively tapped for 
commercial corn seed production, it will be a tremendous benefit for the environment and human health.

\section{Insect Bioassays}

To determine if Tripsacum-diploperennis hybrids are resistant to corn rootworm insect bioassays were conducted by Sun Dance Genetics at the Duke University Phytotron under the auspices of grants from the National Science Foundation Small Business Innovation Research program. In the initial experiment, resistant Tripsacum-diploperennis plants were repotted and then crossed to corn. Those plants were self or sib pollinated then tested in second bioassay to select resistant plants with $50 \%$ of their genes from corn and $50 \%$ from Tripsacum-diploperennis hybrids. Ten bioassays have been conducted to test (Tripsacum- diploperennis X corn) compared to corn, select resistant plants and continue backcrossing to corn.

\section{Experimental Design}

Plants were grown in growth chambers under controlled environmental conditions. Each insect bioassay included three replicates of 128 plants in a randomized block. Plants were grown in 4.5-inch diameter pots with nylon cloth covering the bottom of the pots to prevent larval escape out the holes in the bottom of the pots. Each plant was infested with 70 newly hatched first instar diapausing Western corn rootworm larvae at approximately three weeks post germination. The plants were harvested three weeks after infestation. The roots were carefully washed, then scored using the 1-6 lowa rating scale (Hills and Peters 1971): 1 = no damage or only a few minor feeding scars; 2 = feeding scars evident, but no roots eaten off to within 1.5 inches of the plant; $3=$ several roots eaten off to within 1.5 inches of the plant, but never the equivalent of an entire node of roots destroyed; $4=$ one node of roots completely destroyed; $5=$ two nodes of roots completely destroyed; 6 = three nodes of roots completely destroyed. By Sun Dance Genetics standards, plants that have a root rating of 1 or 2 are resistant. A root rating of 3 is the industry standard for insecticide efficacy of chemical insecticides. After scoring, plants with a root rating of 1 or 2 were repotted in 10-inch diameter pots and transferred to the greenhouse for backcrossing to corn to advance the recurrent selection breeding program for development of isogenic rootworm resistant corn lines.

\section{Marker-assisted Breeding}

Leaf tissue from selected resistant plants was sampled for DNA fingerprinting to identify co-segregating molecular markers. In the summer, field trials were conducted at locations in South Dakota, Minnesota, and Illinois. By working in the Phytotron, 3 to 4 generations a year have been obtained. The recurrent selection breeding program, now at the F14 backcross generation ( $99 \%$ corn), has succeeded in producing essentially isogenic corn lines carrying the corn rootworm resistance trait in less than 4 years. Commercial development of native rootworm resistance in corn is moving forward. With molecular markers for the trait, it will be possible to reduce the time for developing and bringing this new trait to market by two-thirds the time it would take to develop by selecting for the phenotype alone. This is the same or less time required to develop a transgenic product.

\section{GM Rootworm Resistance}

While Sun Dance Genetics has been developing native resistance to corn rootworm, two biotechnology giants have been developing transgenic rootworm resistant corn. Pioneer Hi-Bred and Monsanto are testing the Cry $3 \mathrm{Ab}$ gene from Bacillus thuriengensis that produces a variant insecticidal protein for its ability to confer resistance to rootworm in transgenic Bt corn lines (Ag Biotech Reporter 1999, 2000b). Monsanto planned to introduce Bt corn with rootworm resistance in time for the 2001 growing season, but approval was delayed because of concern that rootworms will rapidly evolve resistance to the gene. Specific resistance from a single gene as in transgenic crops can be highly effective but only for the short term because insect pests rapidly evolve resistance to single gene resistant traits (Duvick 2001). On the other hand, natural resistance provided by a suite of genes as in the Sun Dance Genetics corn lines is more durable and desirable because insects rarely evolve resistance to traits with complex, multi-genic inheritance.

\section{Conclusion}

Practical applications of the work on the origin and evolution of corn for crop improvement provides a clear and safe alternative to genetically modified crops. It can provide time for basic science to thoroughly investigate, identify, and address the many issues and questions about genetic engineering of crop plants. Once the cumulative findings of more thorough, independent investigations into all facets of this revolutionary technology have been conducted, that information will provide the necessary framework to guide formulation of regulatory legislation for more reliable safety tests. Genetic engineering is an exciting new technology that offers a variety of opportunities for solving problems in agriculture in the future, but until we have adequate understanding of what its toxicological impact will be when GM foods are widely dispersed throughout markets, and what its ecological impact will be when deployed into open environment systems, the ancestral genes model provides a reliable method for adaptation of crops to pests, environmental stresses, and climate change that will insure the continuing productivity of the world's food supply. The ancestral genes model incorporates organismal, cytological, and molecular genetics into a framework that enhances conventional plant breeding such that it can be as efficient and effective for crop improvement as transgenic technology. It is a sound, safe alternative to GMOs until the human health, environmental, social, ethical, and policy issues of the application of bio- 
technology in agriculture have been thoroughly assessed and resolved.

\section{Acknowledgments}

I gratefully acknowledge funding for the research under National Science Foundation grant nos. 9801386 and 9660146 to Sun Dance Genetics, and DEB-94-15541 and IBN-9985877 to the Duke University Phytotron.

\section{Literature Cited}

Ag Biotech Reporter. 1999. Maize with rootworm control. AgBiotech Reporter 16 (9):8.

Ag Biotech Reporter. 2000a. Scientist claims transgenes jump. AgBiotech Reporter 17(6):4.

Ag Biotech Reporter. 2000b. Monsanto takes lead in rootworm race. AgBiotech Reporter 17(1):7.

Ag Biotech Reporter. 2001. Horizontal transfer of antibiotic resistance genes. AgBiotech Reporter 18(3):27-28.

American Medical Association. 2001. Report 10 of the Council on Scientific Affairs (I-00): Genetically Modified Crops and Foods. Http://www.ama- assn.org/ama/pub/ print/article/2036-3604.html.

Arnold, M.L. 1997. Natural Hybridization and Evolution. Oxford University Press, New York.

Bennetzen, J., E. Buckler, V. Chandler, J. Doebley, J. Dorweiler, B. Gaut, M. Freeling, S. Hake, E. Kellogg, R. S. Poethig, V. Walbot \& S. Wessler. 2001. Genetic evidence and the origin of maize. Latin American Antiquity 12:8486.

Bennetzen, J. L., \& M. Freeling. 1997. The unified grass genome: synergy and synteny. Genome Research 7:301306.

Berthaud, J., Y. Savidan \& O. Leblanc. 1996. Tripsacum: diversity and conservation. Pp 74-85 in Maize Genetic Resources. ed. S. Taba. CIMMYT, Mexico.

Berthaud, J., Y. Savidan, M. Barr, \& O. Leblanc. 1997. B. Tripsacum. Pp. 227-233 in Biodiversity in Trust, eds. D. Fuccillo, L. Sears, \& P. Stapleton. Cambridge University Press, Cambridge.

Branson, T. F. 1971. Resistance in the grass tribe Maydeae to larvae of the Western corn rootworm. Annals of the Entomological Society of America 64:861-863.
Branson, T. F. \& P. L. Guss. 1972. Potential for utilizing resistance from relatives of cultivated crops. Proceedings of the North Central Branch - Entomological Society of America 27:91-95.

Burkhart, S., B. Kindiger \& A. Wright. 1994. Fatty acid composition of oil from the caryopsis of Tripsacum dactyloides. Maydica 39:65-68.

Charman, K. 2001. Spinning science into gold. Sierra, July/August pp. 40-44.

Chetelat, R.T., C. M. Rick, \& J. W. DeVerna. 1989. Isozyme analysis, chromosome pairing, and fertility of $L y c o-$ persicon esculentum 5 Solanum lycopersicoides diploid backcross hybrids. Genome 32:783-790.

ChŠvre, A.-M., F. Eber, A. Baranger, \& M. Renard. 1997. Gene flow from transgenic crops. Nature 389:924.

Crawley, M.J., S.L. Brown, R.S. Hails, D.D. Kohn\& M. Rees. 2001. Transgenic crops in natural habitats. Nature 409:682-683.

Davies, A., G. Jenkins \& H. Rees. 1990. Chromosome elimination in inter-specific hybrids. Chromosoma 99:289295.

Devine, K. 2000. GM food debate gets spicy. The Scientist $14(21): 10,33$.

Duvick, Donald N. 2001. Breeding of plants. Encyclopedia of Biodiversity, 1:547-558.

Eichers, T.R., P. A. Andrilenas \& T. W. Anderson. 1978. Farmers' use of pesticides 1976. USDA. Agricultural Economics Report No. 418, Washington, D.C.

Eubanks, M.W. 1987. A cytological study of the inheritance of chromosome knobs in maize and its close relatives. M.S. thesis, Vanderbilt University, Nashville, TN.

Eubanks, M.W. 1989. Corn Plant named Sun Dance. U.S. Patent PP6906. Date issued: 4 July.

Eubanks, M.W. 1992. Corn Plant named Tripsacorn. U.S. Patent PP7977. Date issued: 15 September.

Eubanks, M.W. 1994. Methods and Materials for Conferring Tripsacum Genes in Maize. U. S. patent 5,330,547. Date issued: July 19.

Eubanks, M.W. 1995. A Cross between Two Maize Relatives: Tripsacum dactyloides and Zea diploperennis (Poaceae). Economic Botany 49:172-182.

Eubanks, M.W. 1996. Corn Plant named Sun Star. U.S. Patent PP9640. Date issued: 3 September. 
Eubanks, M.W. 1997. Molecular Analysis of Crosses between Tripsacum dactyloides and Zea diploperennis (Poaceae). Theoretical and Applied Genetics 94:707-712.

Eubanks, M.W. 1998. Methods and Materials for Conferring Tripsacum Genes in Maize. U. S. patent 5,750,828. Date issued: 12 May.

Eubanks, M.W. 2001a. The Origin of Maize: Evidence for Tripsacum Ancestry. Plant Breeding Reviews 20:15-61.

Eubanks, M.W. 2001b. An interdisciplinary perspective on the origin of maize. Latin American Antiquity 12:91-98.

Ewan, S.W. \& B. Pusztai. 1999. Effect of diets containing genetically modified potatoes expressing Galanthus nivalis lectin on rat small intestines. Lancet 453:1353-1354.

Gale, M.D. \& K. M. Devos. 1998. Comparative genetics in the grasses. Proceedings of the National Academy of Sciences U.S.A. 95:1971-1974.

Goldburg, R.J. 1992. Environmental concerns with the development of herbicide-tolerant crops. Weed Technology 6:647-652.

Griffiths, A.J.F., J.H. Miller, D.T. Suzuki, R.C. Lewontin \& W.M. Gelbart. 1993. An Introduction to Genetic Analysis. 5th ed. W. H. Freeman, New York.

Hadley, H.H. \& S.J. Openshaw. 1980. Interspecific and intergeneric hybridization. Pp. 133-159 in Hybridization of crop plants eds. W.R. Fehr \& H.H. Hadley. American Society of Agronomy, Madison, Wisconsin.

Hills, T.M. \& D.C. Peters. 1971. A method of evaluating post planting insecticide treatments for control of western corn rootworm larvae. Journal of Economic Entomology 64:764-765.2

Huang, F.L., L. Buschman, R.A. Higgins \& W.H. McGaughey. 1999. Inheritance of resistance to Bacillus thuringiensis toxin (dipel ES) in the European corn borer. Science 284:965-967.

Iltis, H.H., J.F. Doebley, R. Guzman, \& B. Pazy. 1979. Zea diploperennis (Gramineae): A New Teosinte from Mexico. Science 203: 186-188.

Jenkins, G., \& J. White. 1990. Elimination of synaptonemal complex irregularities in a Lolium hybrid. Heredity 64:45-53.

Jenkins, G., J. White, \& J.S. Parker. 1988. Elimination of multivalents during meiotic prophase in Scilla autumnalis. II. Tetraploid. Genome 30:940-946.
Jensen, K.B. 1989. Cytology, fertility, and origin of Elymus abolinii (Drob.) Tzvelev and its F1 hybrids with Pseudoroegneria spicata, E. lanceolatus, E. dentatus ssp. ugamicus, and E. drobovii (Poaceae: Triticeae). Genome 32:468-474.

John, B., \& M. Freeman. 1975. Causes and consequences of Robertsonian exchange. Chromosoma 52:123-136.

Kaiser, J. 2000. Panel urges futher study of biotech corn. Science 290:1867.

Keeler, B. 2001. A nation of lab rats. Sierra, July/August 45.

Kindiger, B.K. \& J.B. Beckett . 1990. Cytological evidence supporting a procedure for directing and enhancing pairing between maize and Tripsacum. Genome 33:495-500.

Kindiger, B.K. \& V. Sokolov. 1998. Apomictic maize. U. S. Patent 5,710,367. Date issued: January 20.

Kuiper, H.A. 1999. Adequacy of methods for testing the safety of genetically modified foods. Lancet 354:13151316.

Leblanc, O., D. Grimanelli, D. Gonzalez de Leon \& Y. Savidan. 1995. Detection of the apomixis mode of reproduction in maize-Tripsacum hybrids using maize RFLP markers. Theoretical and Applied Genetics 90:1198-1203.

Lewis, R. \& B.A. Palevitz. 1999. GM crops face heat of debate. The Scientist 13(20):1 ff.

Linde-Laursen, I., \& R. von Bothmer. 1988. Elimination and duplication of particular Hordeum vulgare chromosomes in aneuploid interspecific Hordeum hybrids. Theoretical and Applied Genetics 76:897-908.

Lord,R.M., \& A.J. Richards. 1977. A hybrid swarm between the diploid Dactylorhiza fuchsii (Druce) Soo and the tetraploid D. purpurella (T. \& T. A. Steph.) Soó in Durham. Watsonia 11:205-211.

Losey, J.E., L.S. Rayor \& M.E. Carter. 1999. Transgenic pollen harms monarch larvae. Nature 399:214.

MacNeish, R.S. \& M.W. Eubanks. 2000. Comparative Analysis of the Río Balsas and Tehuacán Models for the Origin of Maize. Latin American Antiquity 11:3-20.

Mangelsdorf, P.C. 1974. Corn: Its Origin, Evolution and Improvement. Belknap Press of Harvard University, Cambridge, Massachusetts.

Mangelsdorf, P.C. \& R.G. Reeves. 1931. Hybridization of maize, Tripsacum and Euchlaena. Journal of Heredity 22:329-343. 
Mangelsdorf, P.C. \& R.G. Reeves. 1939. The origin of Indian corn and its relatives. Texas Agricultural Experiment Station Bulletin 574:1-315.

McClintock, B. 1984. The significance of responses of the genome to challenge. Science 226: 792-801.

Metcalf, R.L. 1986. Foreword. Pp. vii-xv. in Methods for the Study of Pest Diabrotica. eds. J.L. Krysan \& T.A. Miller. Springer-Verlag, NY.

Meyer, P. 1998. Stabilities and instabilities in gene expression. Pp. 263-227 in Transgenic Plant Research. ed. K. Lindsey. Harwood Academic Publishers, Amsterdam 5 .

Mikklesen, T.R., B. Andersen, \& R.B. Jørgensen. 1996. The risk of crop transgene spread. Nature 380:31.

Moellenbeck, D.J., B.D. Barry \& L.L. Darrah. 1995. Tripsacum dactyloides (Gramineae) seedlings for host plant resistance to the Western corn rootworm (Coleoptera: Chrysomelidae). Journal of Economic Entomology 88:1801-1803.

Moore, G.T., K.M. Devos, Z. Wang, \& M.D. Gale. 1995. Grasses line up and form a circle. Current Biology 5:737-739.

NABC. 1989. Biotechnology and sustainable agriculture: Policy alternatives. National Agricultural Biotechnology Council Report No. 1, Ithaca, New York.

NABC. 1991. Agricultural biotechnology at the crossroads: Biological, social and institutional concerns. ed. J.F. MacDonald. National Agricultural Biotechnology Council Report No. 3, Ithaca, New York.

Nash, J.M. 2000. Grains of hope. Time, July 31, pp. 38-46.

National Research Council. 2000. Genetically Modified Pest-Protected Plants: Science and Regulation. National Academy Press, Washington, D.C.

Nordlee, J.A., S.L. Taylor, J.A. Townsend, L.A. Thomas \& R.K. Bush. 1996. Identification of a Brazil-nut allergen in transgenic soybeans. New England Journal of Medicine 334:688-92.

Obrycki, J.J., J.E. Losey, O.R. Taylor \& L.C.H. Jesse. 2001. Transgenic insecticidal corn: beyond insecticidal toxicity to ecological complexity. Bioscience 51:353361.

Palumbi, S.R. 2001a. The high-stakes battle over bruteforce genetic engineering. Chronicle of Higher Education Chronicle Review April 13, section 2, pp. B7-B9
Palumbi, S.R. 2001b. The Evolution Explosion: How Humans Cause Rapid Evolutionary Change. W. W. Norton and Company, New York.

Raybould, A.F. \& A.J. Gray. 1994. Will hybrids of genetically modified crops invade natural ecosystems? Trends in Ecology and Evolution 9:85-89.

Rieseberg, L.H. \& J.F. Wendel. 1993. Introgression and its consequences in plants. In Hybrid Zones and the Evolutionary Process. R. Harrison, ed. pp. 70-109, Oxford University Press, NY.

Savidan, Y., D. Grimanelli \& O. Leblanc. 1996. Transferring apomixis from Tripsacum to maize: progress and challenges. In Maize Genetic Resources. ed. S. Taba 86-92. CIMMYT, Mexico, D.F.

Singh, R.J. 1993. Plant cytogenetics, CRC Press, Boca Raton, FL.

Snell, M.B. 2001. Against the grain. Sierra July/August:30-33.

Stebbins. G.L. 1950. Variation and evolution in plants. Columbia University Press, NY.

Tantravahi, R.V. 1968. Cytology and Crossability Relationships of Tripsacum. Harvard University Bussey Institution, Cambridge, Massachusetts.

The Economist. 1999. Who's afraid of genetically modified foods? The Economist 351:19-21.

Wagner, R.P., M.P. Maguire \& R.L. Stallings. 1993. Chromosomes: A synthesis. Wiley-Liss, New York.

Wheelwright, J. \& G. Delin. 2001. Don't eat again until you read this. Discover, March, pp. 36-43.

White, J., G. Jenkins, \& J.S. Parker. 1988. Elimination of multivalents during meiotic prophase in Scilla autumnalis. I. Diploid and triploid. Genome 30:930-939.

WHO, 2000. Safety Aspects of Genetically Modified Foods of Plant Origin: Report of a Joint FAO/WHO Expert Consultation on Foods Derived from Biotechnology. World Health Organization, Geneva.

Williams, N. 1998. Agricultural biotech faces backlash in Europe. Science 281:768-771.

Wolfenbarger, L.L. \& P.R. Phifer. 2000. The ecological risks and benefits of genetically engineered plants. Science 290:2088-2093. 
